B 486895

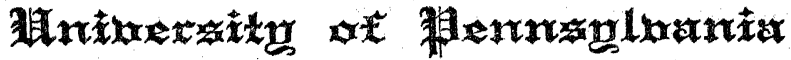

Contributions from the Zoological Laboratory

\section{DESCRIPTIONS}

OF

\section{Two New Leeches from Porto Rico}

BY

\author{
J. PERCY MOORE \\ Instructor in Zoology
}

Extracted from U. S. Fish Commission Bulletin for ryoo, Volume 2. Pages 2 x I to 222 Plates 12 and $\times 3$ 


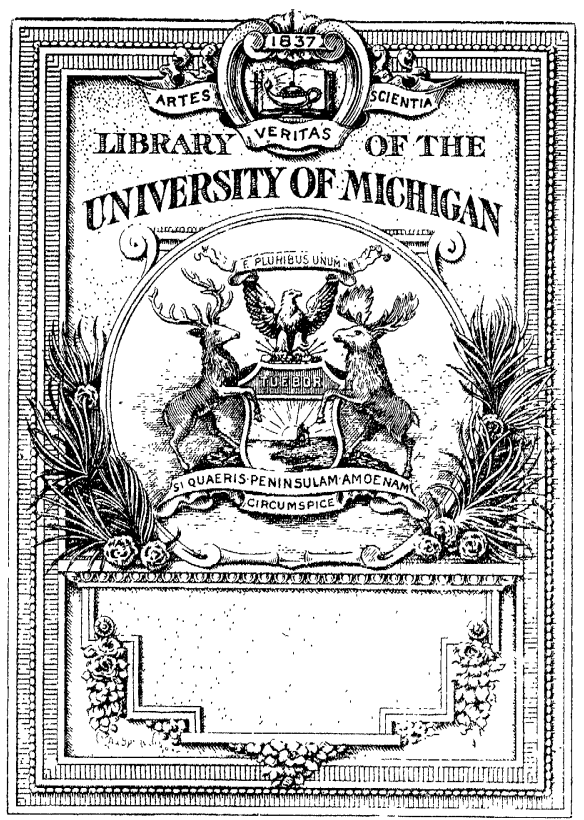




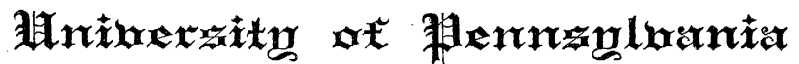

Contributions from the Zoological Laboratory

\section{DESCRIPTIONS}

OF

\section{Two New Leeches from Porto Rico}

BY

\author{
J. PERCY MOORE \\ Instructor in Zoology
}

Extracted from U. S. Fish Commission Bulletin for 1900, Volume 2. Pages 21 i to 222 Plates 12 and 13 
U. S. COMMISSION OF FISH AND FISHERIES, GEORGE M. BOWERS, Commissioner.

\section{DESCRIPTIONS.}

$\mathrm{OF}$

\section{TWO NEII LEECHES FROM PORTO RICO.}

BY

J. PEROY MOORE.

Extracted from U. S. Fish Commission Bulletin for 1900, Volume 2. Pagts 211 to 222. Plates 12 and 13.

WASHINGTON:

GOVERNMENT PRINTING OFFICE.

1901 . 

IESCRIPTIONS OF TWO NEW LEECHES FROM PORTO RICO.

BY

J. PERCY MOORE,

Instructor in Zoology, University of Pennsylvania.

211 


\title{
DESCRIPTIONS OF TWO NEW LEECHES FROM PORTO RICO.
}

\author{
BY J. PERCY MOORE, \\ Instructor in Zoology, University of Pennsylvania.
}

The material under consideration was collected by the expedition sent with the steamer Fish Hawk to Porto Rico in the winter of 1898-99, under the auspices of the United States Fish Commission.

The leech fauna of the West India Islands is very imperfectly known and no fresh-water forms have hitherto been described from the island of Porto Rico. Consequently the two species composing this collection both prove to be novelties. One certainly has and probably both have a much wider distribution.

HIRUDINARIA Whitman (= PECILOBDELLA Blanchard ('93) subgenus).

Hirudinaria was established by Whitman ('86, p. 373) for the Hirudo javanica of Wahlberg, the generic characters assigned being the large size of the posterior sucker, together with the long interval ( $7 \frac{1}{2}$ rings) separating the male and female genital orifices. The great increase in our knowledge of the species of leeches, which we owe so largely to the labors of Blanchard during the last ten years, has rendered such characters, when taken alone, unavailable for generic distinctions. Accordingly Blanchard ('97) has discarded Hirudinaria and has referred the type species to his subgenus Precilobdella of the genus Limnatis. Pocilobdella appears to stand for a very natural assemblage of forms typified by Hirudo granulosa Sav. and especially characterized by the very striking and constant color pattern, which is similar in all of the species included by its author. The described species have hitherto been known only from the tropical and subtropical East Indian islands and Indo-China. Blanchard has indeed mentioned, but without characterizing, a species from the island of Martinique. ${ }^{1}$

The leech described below under the name of Hirudinaria blanchardi may be the Martinique species. It has the typical color pattern of Pocilobdella and resembles Hirudinaria javanica very closely in almost all important features of external organization, but the sex pores are separated by but five rings. I have dissected $H$. blanchardi and find, among other peculiarities of the reproductive organs (pl. 12, fig. 7), that the vagina and the common oviduct open separately into the female bursa (pl. 12, fig. 9). Professor Whitman has very generously placed at my disposal for dissection one of his specimens of H. javanica, in which the female organs, though less mature, present the same peculiarity.

The female organs of Limnatis nilotica (the type species) have been figured by Moquin-Tandon ('46) and Leuckart ('94). In this species the common oviduct opens into the vagina, the mouth of which, therefore, becomes the only internal opening into the bursa, as in Hirudo, etc. On the other hand, $L$. nilotica resembles $I I$. javanica in the numerous small uniserial denticles and the papillæ which are found on the sides of the jaws. Limnatis, as understood by Blanchard, is naturally divided by the character of the female reproductive organs into two genera, the one typified by L. nilotica, the other by $H$. javanica. The latter is the Pecilobdella group and will probably be found to include all of the species which have been referred to that subgenus; but for this genus the name Hirudinaria Whitman has priority.

A revised diagnosis of Hirudinaria based upon an examination of the type species and $H$. blanchardi is as follows: Resembling Limnatis in external annulation, lips, and jaws; the common oviduct and vagina have separate openings into a small bursa; the segmental sensillæ are large and usually elongated

1 From this island also three nominal species, referred to Hirido and Hramopis Moq.-Tan., were long ago described by Moquin-Tandon and Blainville. The habits of at least one of these suggest a Limnatis or IHirudinaria, but there is nothing in the descriptions of any of the three sufficient to identify it with the Porto Rican species. 
in shape; the denticles are small and very numerous; some of the pharyngeal glands open on conspicuous papillæ on the sides of the jaws. To this the color pattern as described by Blanchard for Pocilobdella will probably need to be added.

\section{Hirudinaria blanchardi, sp. nov.}

Diagnosis. - Genital pores separated by five annuli, the male being situated at $\times 165 / 6$, the female at $x i m b 5 / 6$. Annulation as in $H$. javanica (Wahlberg) Whitman, except that xxivb5 and $b 6$ and $x \times v b 1$ and $b 2$ are developed (that is, the annuli numbered 95 and 96 in Whitman's figure ('86, pl. $\mathrm{xx}$, fig. 56) are in the present species each represented by two partially separated rings).

Named for Prof. Raphael Blanchard, of Paris.

External characters. - All of the examples are very much contracted. The type specimen, which is of medium size, measures as follows: Length, $39 \mathrm{~mm}$.; greatest width (XvII or XIX), $11 \mathrm{~mm}$.; depth at same point, $5.6 \mathrm{~mm}$; diameter of mouth at base of upper lip, $2.5 \mathrm{~mm}$; diameter of sucker, $6 \mathrm{~mm}$. The species reaches a much larger size, probably equaling our Macrobdella decora. The largest example is $64 \mathrm{~mm}$. long and its greatest width is $18.5 \mathrm{~mm}$., but most of those in this collection are much smaller, being from $15 \mathrm{~mm}$. to $25 \mathrm{~mm}$. long. -

Owing chiefly to their contracted state the larger examples are short and thick, slightly depressed behind but becoming more and more terete toward the mouth. The greatest width occurs at the beginning of the posterior third, in which region the dorsal surface is much more convex than the ventral, as indicated in fig. 4, plate 12 , by the greater distance $m \mathrm{dm}$ than $m \mathrm{vm}$. A strong annular contraction occurs in all the smaller examples at about somites viI and Ix, resulting in the appearance of a short rounded head united by a neck to the body, which is of a flattened, narrow, elliptical form. The lips and margins of the mouth are so much contracted that the folds which lie anterior to the jaws, and in some examples even the jaws themselves, are plainly visible. This would indicate that under normal conditions the mouth is of large size, as in H. javanica. No distinct clitellum is indicated.

There are 104 annuli, beginning with the prostomium and ending with the postanal annulus at the base of the acetabulum (pl. 12, figs. 2 and 3). Owing to contraction they become very short and crowded at the posterior end, but much less so anteriorly. The annuli are marked off into quadrate areas, each of which contains one or more pointed papillæ and very numerous smaller sense organs (pl. 12, fig. 4). The larger papillæ become very prominent posteriorly and at the margins of the body. Some further details are added below in connection with a description of the annulation and metameric sensillæ.

The broad upper lip consists of the preocular region, here counted as one somite and one annulus, together with the first three eye-bearing annuli and the fifth annulus (pl. 12, figs. 1 and 2). Like the remainder of the body, this region is roughened by numerous non-segmental papillæ. A deep longitudinal median sulcus (pl. 12, fig. 1) divides the lower surface of the lip, as in Limnatis, into equal halves. Posteriorly this sulcus widens into a triangular depressed area from which the median jaw rises. On each half of the lip are about three less deep sulci about equidistant and extending parallel to the median one. Between these the lip is nearly smooth, but is studded with numerous minute sense organs, which are especially plentiful near the anterior margin. The mouth is bounded posteriorly by the coalesced sixth and seventh annuli (pl. 12, fig. 1).

A full somite separates the sex pores, the male being situated at $x \leq b 5 / 6$, the female between the corresponding annuli of xir. Both of these orifices are inconspicuous and not indicated by any elevations, glandular areas, or pits. The male pore is somewhat the larger, but in no case does the penis protrude. No clitellum is visible even on the largest specimens. Nephridiopores are found in the position and number usual in the family ( $\mathrm{pl}$. 12, fig. 4, np.). They are placed exactly on the inner margin of the ventral black band.

The posterior sucker (pl. 12, fig. 3), like the posterior region generally, is much contracted, but still large. Its anterior margin reaches as far forward as somite xxiII, so that when relaxed it would probably have the size and proportions of the corresponding part in $H$. javanica. Dorsally it is marked by six or eight irregular transverse wrinkles, and is somewhat roughened and bears papillæ, as in the body annuli. Numerous elongated sensillæ are also found here, but they vary much in number, size, and position in different individuals. Ventrally, the sucker in its contracted state is more or less funnelform, with a deep central depression and sloping sides which are marked by numerous faint radiating furrows. The anus is of small size and is situated between somite Xxvir and the base of the sucker. 
Annulation.-In the following description of the annulation, the annulus bearing the metameric sensillæ is regarded as the middle one of the complete somite (see Castle, 1900, and Moore, 1900). The description further serves to show how this view works out when applied to one of the five-ringed Hirudinidx. This leech possesses fifteen typical complete somites, being Nos. Ix to xxm, inclusive (pl. 12, figs. 1, 2, and 3). The five rings constituting each are of approximately equal length, but, as indicated by the symbols on figures 2 and 3 , they have very different morphological values, the middle annulus being equal to the first plus the second, and to the fourth plus the fifth. (See Moore, '98 and 1900.)

The structural details of the exterior of the complete somite $x v$ are shown in figure 4, plate 12, the portion included between the lines $d m$ and $m$ representing the dorsal surface and between $v m$ and $m$ the ventral surface. Owing probably in part to the accidents of contraction, the annuli are of irregular length; they overlap somewhat at the posterior margin, and are in places marked by slight wrinkles, usually running transversely. More definite and constant longitudinal furrows, which tend to alternate in position on adjacent annuli, divide the surface into quadrate areas. According to their size, these areas bear one, two, or more of the conical sense organs each elevated on a papilla and surrounded by a group of small goblet-shaped organs and sometimes by smaller conical organs. When not too much displaced by contraction, these papillæ form a range along the middle of each annulus. They vary much in size in different places and individuals, but are especially rough and prominent at the margins and posterior end of the body.

The middle annulus, in addition to these non-metameric organs, bears seven pairs of very conspicuous metameric sensillæ which have the large size, the shape, and inclined position so well represented in Whitman's ('86) figure of H. javanica. Typically four pairs of these are dorsal (pl. 12, fig. 4), the dorso-median $(m d)$, the dorso-lateral $(d l)$, the dorso-marginal $(d m a)$, and the supramarginal $(\mathrm{sm})$; three pairs are ventral, the submarginal $(\mathrm{sbm})$, the ventro-marginal (vma), and the ventro-lateral $(v l)$. They are of elliptical outline with a rather prominent axial ridge, along which a narrow white line (of transparent cells) runs. The dorso-median pair are broadly elliptical, situated close together with only one quadrate area intervening and inclined to the median plane at an anterior angle of about $30^{\circ}$. The dorso-lateral pair have the same form, but are of slightly larger size, being the largest of the segmental sensillæ. They are separated from the dorso-median by three or four quadrate areas, and lie almost exactly midway between the marginal line and the latter. They incline to the median plane at an angle of approximately $45^{\circ}$. The dorso-marginal are long and narrow and their inclination to the median plane approaches closely, or even reaches, $90^{\circ}$; they are commonly separated from the last described by three quadrate areas. Much smaller are the supramarginal organs, which vary much in shape, size, and position.

The ventral sensillæ are all of approximately equal size and similar shape; the ventro-lateral have an inclination of about $35^{\circ}$ and the others of about $90^{\circ}$ to the median plane. The ventro-lateral and ventro-marginal lie closer together and nearer to the median line than the corresponding organs above. Of course, the angles of inclination vary and in any case can not be measured very accurately, so that the angular inclinations given are only approximate. The sensillæ situated at the margins of the body are peculiarly inconstant. Frequently one is represented by two or three smaller ones, or may become minute or altogether suppressed, or two may apparently unite into one, which occupies an intermediate position.

Toward the anterior end the first incomplete somite met with is No. virI. Annuli $a 2, b 5$, and $b 6$ are precisely as in the following somites. On the dorsal side $b 1$ and $b 2$ are still distinct, but much shorter, and the furrow which separates them has become faint. On the ventral side the furrow extends only a short distance mesiad from the margins, but the two rows of sense organs are apparent almost to the niddle line, at which point the ring becomes entirely undivided, representing $a 1$. On somite vin the corresponding annulus exhibits a slight trace only of the furrow $b 1 / b 2$ on the middle of the dorsal surface, but two rows of sense organs persist to the margins or even onto the ventral surface. Annuli $b 5$ and $b 6$ present exactly the same condition as do $b 1$ and $b 2$ of the succeeding somite (VIII). $\mathrm{vI}$ is a typically triannulate somite above, but on the middle part of the ventral surface the furrow between $a 1$ and $a 2$ has disappeared. The distinction between these two annuli is preserved across this space, however, by the persistence of two series of sense organs. On the dorsal side the presence of double series of sense organs on $a 1$ and $a 3$ suggests the growth potentiality of these rings also. On this somite the sensillæ of the dorso-lateral pair become modified as the last pair of eyes, which are the smallest of the series and have their axes directed outward and backward. Somite v is biannulate dorsally, with a faint partial furrow incompletely dividing the anterior annulus into two. Anterior to 
this furrow is a complete transverse series of non-segmental organs, and posterior to it another and the metameric organs, including a pair of eyes. Ventrally this somite bounds the mouth posteriorly and is represented by a single annulus. Somite iv is also biannulate. The two annuli are of nearly equal width, or the first slightly the wider. That the latter represents $a 1$ and $a 2$ seems evident from the presence of traces of a furrow passing anterior to the eyes and lateral sensillæ, and by the presence of an additional series of organs anterior to this furrow. The dorso-median sensillæ have moved forward slightly anterior to the traces of this imperfect furrow. Somite III is very imperfectly biannulate, the faint cross furrow not continuing to the margins. The non-segmental sense organs, though reduced in number, form two complete transverse rows. This somite is further interesting because it bears two pairs of eyes, the outer belonging to the dorso-lateral series and being the largest and most anterior of this series. They are crowded toward the posterior margin of the anterior incomplete ring. The second pair of eyes represent the dorso-median sensillæ and have moved forward to become included in a common pigment mass with the eyes on somite II. Whitman ('92) has described a similar condition in Clepsine (Placobdella). The eyes of this sixth pair are of small size and were detected only upon the examination of sections. Somites I and II are only imperfectly separated by a partial and slight furrow, which in many cases appears to be wanting altogether. The first pair of eyes is situated on the posterior part of the annulus representing II, but the other metameric sensillæ are very small and difficult to distinguish from the scattered organs.

Considering the anterior end as a whole it will be seen that the transition from the uniannulate or even coalesced somites of the prostomium and lip to the complete quinque-annulate somite is a very gradual one. The appearance of a new ring is first heralded by the gradual separation of an additional row of non-metameric sense organs, then by the appearance in the dorso-median region of a faint furrow, which travels toward the margins, becomes gradually deeper, and creeps around to the ventral side toward the median line, where it finally becomes complete. These processes are always more advanced ${ }^{1}$ in the posterior than the anterior portion of the somite, and in every stage of development, from the beginning biannulate somite III to the nearly complete somite vIr, the portion of the somite posterior to $a 2$ is more fully developed than the anterior portion.

At the posterior end (pl. 12, fig. 3) the series is run through more rapidly, and owing to the crowding of the annuli the arrangement of the non-metameric organs could not be satisfactorily worked out. Somite XxIrI is complete. On Xxiv the two posterior annuli ( $b 5$ and $b 6$ ) are short and the dividing furrow faint or sometimes obliterated in the middle part. Somite $\mathrm{xxv}$ is quadri-annulate, $b 5$ and $b 6$ being represented by $a 3 ; b 1$ and $b 2$ are also shorter and not fully developed on the ventral sides. These two somites, therefore, are more differentiated anteriorly than posteriorly; that is, like the anterior somites they are developed from the end toward the center of the body. There is a sudden change from the four rings of $\mathrm{xxv}$ to the two of $\mathrm{xxvI}$, and there is here no definite clue to the whereabouts of the rings ( $b 1$ and $b 2$ ) which, as such, are wanting in somite XxvI and in xxvI, which is precisely similar. These two somites also differ from those which immediately precede them in their stronger posterior development. They may, therefore, be compared with the anterior biannulate somites III, IV, and $\mathrm{v}$, in which the easy transitions show conclusively that the annuli $b 1$ and $b 2$ belong potentially to that portion of the anterior and usually larger annulus which lies anterior to the metameric sensillæ. The almost universal position of the latter on the posterior part of the annulus gives added force to this view. The resemblance of such biannulate somites to the complete somites of Microbdella has already been pointed out (Moore, 1900), and it need only be added that the persistence of this type of somite at both ends of the leech's body, under mechanical conditions which appear to stimulate neighboring somites to growth in opposite directions, is significant of a probably phyletic meaning.

Three and sometimes even all four pairs of the dorsal sensillæ may be traced serially on the posterior sucker; but they are very irregularly developed, sometimes multiplied by division, sometimes reduced in number by concrescence or suppression and always variable in position, so that they have little value in the determination of metamerism (pl. 12, fig. 3).

Color.-The smaller examples only present a distinct color pattern, which becomes more obscure and diffuse with increase in size. Some specimens have been preserved in formalin, and the colors are described from these; but they probably have undergone some alteration, so that only the pattern is significant. Of a specimen measuring $22 \mathrm{~mm}$. in length the ground is a clear reddish clay color,

1 It is assumed for deseriptive purposes that the process of development is a progressive one by increasing complexity from before backward. 
becoming a dull orange on the ventral surface, where it forms a continuous uniform area occupying about two-thirds of the width of the body and entirely uninterrupted by any markings. At the sides this area is delimited by a pair of sharply contrasting broad bands of dull black, in the borders of which are scattered some irregular spots of deeper black. External to the black bands, and marking the exact margins of the body, are two narrower bands of the ground color, but somewhat paler than the ventral surface. The dorsal color pattern produces a very beautiful effect. Briefly stated, it consists of five dark longitudinal bands, separated by four of the ground color, which also appears more or less within the dark bands. Of the five latter the unpaired one is the widest and is divided along the median line into halves by a regularly broken line of vivid black, which is flanked at intermetameric intervals by pairs of black spots. A pair of narrower supramarginal bands bear upon their outer flanks regularly arranged outstanding black spots, between which and the yellow marginal stripes the ground color becomes of a nearly pure olive. The intermediate bands, or second pair, are still narrower and are situated about midway between the median and supramarginal bands.

Inasmuch as the color pattern of this species throws much light on the character of the segmentation of the body a further description, especially of its metameric features, is now given. When further analyzed each of the dark bands is seen to be composite, being constituted of longitudinal elements or narrower lines, which are the result of the greater or less admixture of black pigment with the ground color. In general the dark pigment is more dense along the margins of the bands, resulting in the formation of narrow black borders to sooty or clouded olive stripes. The bands are further made up of serial units, the metameric and intermetameric distribution of which is expressed in each by an evident tendency to widen in the middle and to shrink or even become suppressed at the ends of somites. Each band consists, therefore, of a series of metameric enlargements, alternating with constrictions, which are here termed intermetameric because they extend over the contiguous portions of two adjacent somites (as somites are determined in this paper). In complete and typical somites the metameric elements belong to the three middle annuli $(b 2, a 2$, and $b 5)$, while the intermetameric are confined to the first and fifth $(b 1$ and $b 6)$; but in the entire series the last annulus of one somite is united with the first of the succeeding somite in respect to color effectiveness (pl. 12, fig. 4).

The metameric elements (fig. 4) are found: (1) In both borders of the middle and intermediate bands and the ental border of the lateral, all of which become much more sharply defined or of a deeper black in the three middle annuli and more diffuse and obscure or entirely suppressed on the terminal annuli. (2) In the median black line, which, as above noted, is not continuous, but formed of a series of short black dashes, each of which is a bold distinct stroke extending over the three middle annuli and interrupted by light areas on the first annulus and the fifth. Usually there is no blending of successive dashes, but sometimes the intervening areas become more or less suffused with black pigment, which is more likely to occur on the first than on the fifth annulus. (3). In the black spots which lie on the onter borders of the lateral bands. These are of a deep black color and occur constantly on the second (b2) and fourth (b5) annuli, respectively anterior and posterior to the dorso-marginal sensillae, around the internal side of which they are connected by a delicate arch of black pigment. To these positive elements may be added some negative elements: the light spots of more or less pure ground color which are included within the widened portions of all the bands, viz., a pair flanking each segment of the median black line of the unpaired band, a series of similar spots in each of the intermediate bands, and less distinct ones in corresponding positions in the lateral bands.

The intermetameric elements (pl. 12, fig. 4) of the lateral and intermediate bands are the rather negative features of the contracted regions on the first and fifth annuli. Here the black borders lose their intensity, and the black pigment becomes diffused and distributed almost uniformly across the whole width of the bands, thus separating from one another the light serial spots above mentioned. In the corresponding parts of the median band the black pigment becomes largely concentrated into a pair of intense spots, extending over the fifth $(b 6)$ and first (b1) annuli, and including between them a more or less clear light spot, the repetition of which causes the series of breaks in the median black line above mentioned.

On the incomplete somites at the anterior end all of these markings may be distinguished, and as they retain their exact relative positions they afford an important clue to the homology of the developed annuli. All five of the bands become more distinctly constricted intersegmentally, the intermediate pair finally breaking into two series of elliptical spots and the lateral similarly into series of crescents, the horns of which embrace the dorso-marginal sensillæ. On somite virr, in which the annuli $b 1$ and $b 2$ are incompletely developed, the median black dash extends over $a 2, b 5$, and the 
posterior half (representing $b 2$ ) of the first annulus, while the paired spots are confined to the anterior half (b1) of this annulus. The black pigment of the intermediate band is entirely, and that of the lateral band nearly, absent from the fifth $(b 6)$ annulus, while the anterior portion of the first or double annulus ( $b 1$ and $b 2$ ) is also free from black pigment. On the triannulate somites VII and VI this arrangement is still more striking, and the exact composition of the first and third annuli is indicated by the extent of the metameric and intermetameric pigmentation. The median black dash, the intermediate ellipses, and the lateral crescents on each occupy the middle annulus and about the adjacent one-half of the third $(a 3)$ and two-thirds of the first $(a 1)$ annuli, while the paired intermetameric spots are confined to exactly the remaining fractions of annuli $a 1$ and $a 3$. These parts have exactly the values which were assigned on other grounds to $b 1$ and $b 6$ in the composite annuli. Even on the biannulate somite $v$ the pattern remains; the median dash becomes a mere spot, which occupies about the posterior three-fourths of the first ( $a 1$ and $a 2)$ and the anterior half of the second (a3) annulus. Anterior to this the median line becomes continuous over somites IV and III to a point between the first pair of eyes, where it meets the light color of the lip margin. The remains of the intermediate and lateral bands, and especially the intermetameric spots of the median band, serve to define the potential annuli even on somite Iv, the last named extending onto the posterior part of III. It will be seen that the study of the color pattern of this species confirms to the last detail the values which were assigned to the annuli as a result of the study of sense organs, integumental furrows, etc. Further, it affords support to the neuromeric standard for limiting the somite.

At the posterior end of the body a similar relation between the color markings and the somite constituents appears to be maintained, but the condition of the material prevents its being satisfactorily worked out. The posterior sucker is marked above by an irregular ring of black inclosing a light spot and flanked by a few black rays; the ventral surface is ash-colored, with a few small scattered black spots, mostly near the margin.

Small specimens are still brighter in color. The ground is purer and clearer, sometimes paler, sometimes redder, and the black markings relatively deeper and more vivid. As the size increases there appears to be a progressive tendency for the black pigment to diffuse over the entire dorsal surface, changing the ground color to a dull olive and entirely obscuring the markings, though the more important black spots may always be found. The largest specimen is of a nearly uniform brown olive, with faint darker cloudings, spots, and broken lines, among which may always be distinguished the median series of dashes, the paired intermetameric spots, and the lateral spots. They are very obscure, but sufficient to show the persistent impress of the original pattern.

Alimentary Canal. - The mouth cavity is bounded posteriorly by three broad triangular folds, a single median ventral and a pair of dorso-lateral, together forming a diaphragm, through the limbs of the trifid aperture of which the anterior edges of the three jaws are usually visible. Slight, grooves run along the bases of the dorsal folds and meet in a triangular expansion of the median labial : ?

Except that the median dorsal jaw is somewhat lower, the three jaws (pl. 12, fig. 5) are of simiar shape-long, low, and compressed, with the edge only slightly convex. They are strongly angulated anteriorly, where they pass abruptly into the supporting plate, but recede more gently behind. The denticles (pl. 12, figs. 5 and 6) are very small, triangular plates set transversely on the jaws, and number from 160 to 180 on each jaw in the two examples which were examined. They are largest anteriorly, where they measure $0.03 \mathrm{~mm}$. in height, and diminish gradually to one-half that height at the posterior end. Along the sloping sides of each jaw are considerable numbers of button-shaped papillæ supported on narrow stalks. They vary in size, the largest being about $0.07 \mathrm{~mm}$. in diameter, the smallest about one-fourth that size. Most of them are arranged somewhat in three irregular rows (fig. 5) of about ten each, between which some smaller ones are scattered. They appear not to be sense organs, but serve as places of exit for some of the ducts of the pharyngeal glands, most of which traverse the interior of the jaw and open on its ridge between the teeth. Possibly it is due to the great number and crowding of the denticles that additional outlets are required for the glands.

The muscular œsophagus is marked by six longitudinal folds, the three which correspond to the jaws being larger than those which alternate with them. It reaches to somite Ix. There are ten pairs of gastric cæca developed, as in Hirudo. The last originates in xIx, is large, sacculated, and extends caudad. None of the smaller creca are much sacculated. That this species is a true bloodsucker is shown by the presence of blood in the cæca of all specimens examined.

Reproductive Organs. - A general view of the reproductive organs is shown in pl. 12, fig. 7 . The male organs do not differ in any important respect from Finudo, thongh the sperm sacs (de) are larger. 
There are eleven pairs of testes $(t 1-t 11)$ resting on the ventral longitudinal muscles on each side of the nerve cord and immediately behind their corresponding ganglia. The sperm ducts $(v d)$ lie on the floor of the body just external to the testes, and, owing in part to the contraction of the body; are greatly convoluted. At the posterior end they extend beyond the last pair of testes as short, blind tubes, but a sufficient number has not been dissected to show that this is a constant feature. At the anterior end the ducts become much smaller, less glandular, and less convoluted. In somite xI they bend back on themselves and immediately become wide, irregular, closely convoluted tubes, forming rather compact masses, the epididymés $(e p)$. At their posterior end these again pass into the small ends of the conspicuous fusiform, muscular-walled sacs, the ducti ejaculatorii, or sperm sacs (de). Finally the two sperm sacs unite in a common penis sheath (figs. 7 and 8 ps.), which is a thick, muscular, pyriform sac bent sharply forward on itself and attached to the ventral body wall at the male orifice. There is a long coiled-up penis, but in no cases was it found to be protruded. Prostate glands are scarcely evident, only a few solitary unicellular glands opening into the bulb of the penis sheath.

The peculiarities of the female organs (pl. 12, figs. 7 and 9) have already been mentioned in the generic description. The vagina $(v g)$ is cylindroid in younger specimens, but becomes much enlarged at the blind end, with a relatively narrow neck (fig. 9) in fully mature examples, in which also it may become doubled on itself. The two "ovaries" (ov) lie about equidistant from the middle line and their ducts empty into a common oviduct with a small albumen gland ( $g l a)$. The common duct is short and folded into a compact coil which is bound to the anterior wall of the vagina, with which it opens, but by a separate orifice, into a small and probably eversible female bursa $(b)$.

The female organs of $H$. javanica are shown on pl. 13, figs. 18, 19, and 20. The specimen, although much larger than that from which fig. 7 was drawn, is much less mature. The structure of the organs is in every respect similar. The vagina is marked by longitudinal wrinkles and it projects upward almost vertically from the ventral body wall, carrying the nerve cord with it.

Several specimens (about fifteen) of various sizes were taken from a bottle labeled "Cagua 1-10-99."

DIPLOBDELLA, gen. nov.

The leech for which this genus is proposed belongs to the monostichodont Hirudinidx and differs in several respects from all members of this group whose internal anatomy has been described. The sperm ducts of the two sides remain entirely distinct almost to the external orifice, with which they are connected by a very short canal. There is no definite and distinct penis sac, and if the common canal is eversible at all it can form only a very short penis. There is a remarkable development of gastric cæca, most of the complete somites as far back as XviI having two pairs in place of the one usually present. These are-always very obvious and the two pairs are of equal length in some of the postgenital somites. There is frequently a tendency for most of the annuli to become faintly subdivided. (See pl. 13.) This disposition toward the doubling of organs has suggested the name.

The nearest ally of Diplobdella known to me appears to be Philobdella Verrill. This genus has the sperm ducts similarly separated almost to the external orifice, the prostate glands very large, the jaws high and few toothed, and the color pattern similar. But it differs in the complicated copulatory glands and pits, in the much simpler lobing of the stomach, the form of the ovaries and vagina, and, in the known species, in the location of the sex pores and some details of annulation. Macrobdella Verrill possesses the two pairs of gastric ceca per somite, but the male reproductive organs are quite dissimilar.

None of the numerous descriptions of Hirudinidæe from South and Central America, etc., appear to fit the type species, which is therefore described as

Diplobdella antellarum, sp. nov.

Diagnosis.-The sex pores are separated by $3 \frac{1}{2}$ rings, the male being situated at $\frac{\mathrm{XI}}{\mathrm{XII}}$, the female at the middle of xu 65 . There are about 35 denticles on each jaw. Annulus xxvi $a 1$ is developed at the inargins. Annulus iv a3 is frequently imperfectly differentiated. The colors are plain ventrally, longitudinally striped above.

External Characters. - When fully extended this leech is slender and the sides of the body nearly paraliel for a long distance, as in a nephelid; when strongly contracted, which is the state of most of the specimens, the body is nearly elliptical with bluntly rounded ends. Whether contracted or 
extended, the body is always flattened, quite unlike the thick rounded form assumed by Hæmopis, etc., when contracted or resting. The largest extended specimens are over 3 inches long. The selected type specimen has the following dimensions: Length, $55 \mathrm{~mm}$.; greatest width (about xvir), $8.5 \mathrm{~mm}$.; greatest depth, $3.8 \mathrm{~mm}$. (about); diameter of sucker, $5.4 \mathrm{~mm}$; width of upper lip at base, $2.3 \mathrm{~mm}$.

There are 105 distinct annuli, counting one which appears posterior to the anus. In many specimens most of them are marked by a transverse depressed line, making them faintly double. The annuli are smooth, in no case exhibiting the prominent papillæ so characteristic of the species last described, although in some cases examples of the two species had been killed and preserved together.

In marked contrast to Hirudinaria blanchardi the mouth is relatively small. The upper lip is slightly wrinkled on the margin, but nearly smooth below, and undivided by a median sulcus except at the base. Dorsally it is seen to consist of the first four somites, the coalesced annuli of the fifth bounding the mouth posteriorly.

The five pairs of conspicuous eyes (pl. 13, fig. 10) are disposed as usual in the family. The different directions toward which their pigment cups face is especially evident. The first pair look directly forward, the second forward and slightly outward, the third outward, the iourth outward and backward, and the fifth backward and slightly outward.

The male pore is situated on a small, more or less prominent cone rising from the contiguous parts of somites XI and XII, between which the orifice lies. In no case does a penis protrude, and there are no copulatory glands. The female pore opens through the middle of the fourth annulus (b5) of somite XII. (Pl. 13, fig. 12.) None of the specimens show a clitellum.

The anus has the usual position behind somite XXvII, but XXvIII appears as a distinct ring bounding it behind. The sucker is relatively small, thin, very flat, rather narrowly attached, and much more broadly free posteriorly than anteriorly (pl. 13, fig. 11). The usual 17 pairs of nephridiopores appear as short oblique slits on the posterior margins of annulus $b 2$ of every somite from virI to Xxrv, inclusive (figs. 10 and 11). The first 16 pairs are just ectad of the ventro-marginal sensillæ; the last pair is peculiar in being distinctly more mesiad.

Annulation.-The details of annulation are sufficiently shown in the diagrams (pl. 13, figs. 10,11). Attention is directed to the following points: Somites II and III are very short, with no trace of more than one annulus each. The second annulus $(a 3)$ of iv is sometimes very imperfectly separated. On the ventral surface $\mathrm{v}$ is uniannulate and $\mathrm{v}$, biannulate. viral is very large, but always entirely undivided; $\mathrm{XXVI} \alpha 1$ is separated at the margins at least, the first annulus $(\alpha 1+\alpha 2)$ of $\mathrm{Xx}$ II is very broad, and its sensillæ are far posterior, and, lastly, xxvirI appears as an annulus distinct from the sucker.

The metameric sensillæ (pl. 13, figs. 10 and 11) are small and round as in Hæmopis and Hirudo medicinalis, but are generally easily found. The dorso-lateral are much larger than any of the others. Their arrangement is shown in the figures, the three ventral pairs on somite XIV (fig. 10). Sensillæ are very numerous on the dorsal surface of the sucker, all of the eight dorsal series being well represented. As usual, they are variable in number and position and show evidences of multiplication.

Color.-The pigmentation is described from formalin specimens, which have probably faded considerably. The colors are very quiet and the pattern simple, but both tint and arrangement vary greatly. The ventral surface is of a uniform ash, which sometimes has a distinctly reddish tint, in which case there is likely to be a slight submarginal band clouded with black. A narrow yellowish band varying in intensity extends along each margin. Dorsally, the ground color may be just like the ventral or it may be darker or tinged with yellow. In a typical example there are three pairs of dark longitudinal bands, which together occupy about two-thirds of the width of the dorsum and unite at the ends of the body. They are of an olive color bordered by narrow margins of brown. The innermost pair are the broadest and are separated by a narrow but distinct line of yellowish. The intermediate pair is slightly and the lateral pair much narrower, and the latter is frequently broken and interrupted by intrusions of the ground color. Between the dark bands the intervening strips of ground color are very narrow, and broken here and there by bridges of the dark pigment, which cross more frequently between the lateral and intermediate bands. Such connections are most likely to occur on the fourth annuli of somites, but the pigmentation of this species appears to have no constant metameric characters. All of the dark bands coalesce in a single spot of pigment which surrounds the anus and extends onto the sucker in the form of a crescent.

The extreme of color on the one hand is found in a type in which the pigmented bands become of an inky black, the median yellow line is almost obliterated, and an additional dull black supra- 
marginal line appears, and on the other in an example in which the dorsal markings have become very obscure and pale, so that the entire animal is of a nearly uniform reddish ash color. Intermediate examples are found.

Alimentary Canal. - The jaws are much like those of Hirudo, conspicuous, high, short, and compressed, bearing a relatively small number (about 35) of denticles arranged in one series (pl. 13, fig. 13). They are much larger on the anterior part of the jaw, becoming smaller and relatively broader posteriorly, where they are succeeded by several imperfectly developed ones. All of the functional denticles bear recurved calcareous tips. There are no lateral papillæ, but all of the gland ducts empty on the jaw ridge between the teeth (fig. 13).

A very remarkable feature of the alimentary canal is the extensive development of gastric creca. Each complete somite from virI to XVIII contains two pairs instead of the one pair only, which is usual. In the more anterior of the somites named these cxeca are of relatively small size and are irregularly developed, but in the more posterior the ceca of the two pairs are of equal and large size, and considerably lobed. The last cæca arising in XIx, as usual in the Hirudinidx, are very large and extend posteriorly by the sides of the intestine into somite xxIV (pl. 13, fig. 17).

Reproductive Organs.-Ten pairs of testes (pl. 13, figg. 14, t1-t10) occur in as many somites (xI to xx). The last are very small and terminate the sperm ducts. The latter $(v d)$ have a narrow muscular (?) section in somites $\mathrm{xI}$ and $\mathrm{xI}$. The epididymes $(e p)$ are large curved masses which open into sperm sacs $(d e)$. The sperm sacs themselves (figs. 14, 15, and 16, de) are comparatively small, and present the remarkable feature of being closely bound together by muscular and especially by connective tissue sheaths. Moreover, they are concealed from above by a thick layer of prostate glands ( $p g l$ ) which completely cover them dorsally, laterally, and posteriorly, and which open by numerous ducts into the sperm sacs themselves. In a dissection the epididymes appear to terminate in a somewhat massive median body which, by sectioning, is found to include the sperm ducts, as just described. The common median portion of the sperm ducts, corresponding to the penis sheath of most Hirudinidx, is a very short atrium with very thick muscular walls $(\mathrm{mb})$ and a rather wide lumen lined by a somewhat folded epithelium $(m)$. There is no indication of a long filiform penis, such as occurs in most jawed leeches, and while the lining of the atrium is probably eversible, it could form only a very short, rather wide penis. The structure of the whole region would appear to adapt it better to the production and placing of spermatophores, as in Glossiphonia, rather than for copulation as practiced by Hirudo.

The female organs are like those of Hirudo, etc. The vagina $(v g)$ and slightly folded common oviduct $(o d c)$ lie to the right of the nerve-cord, ventral to which the left oviduct crosses to join the latter.

Like $H$. blanchardi, this species is a blood feeder, as is evidenced by the presence of blood in the cxeca, etc. A large number of specimens were collected at San Juan on January 12, 1899, and at Cagua on January 10, 1899. It also occurs on the American continent, as I have received from Professor Harold Heath, of Leland Stanford University, examples collected by R. C. McCregor in January, 1896, at Panama, Colombia. The drawings of the internal anatomy were made from the latter.

\section{LIST OF PAPERS CITED.}

Blanchard, R., 1893. Révision de Hirudinées du Musée de Turin. Bollettino dei Musei di Zoologia ed Anatomia comparata della R. Università di Torino. viIr (1893), 1-32.

Blanchard, R., 1897. Hirudinées du Musée de Leyde. Notes from Leyden Museum. xix (1897), $73-113$.

BAYER, E., 1898. Hypodermis und neue Hautsinnesorgane der Rhynchobdelliden. Zeitschrift f. wissenschaftliche Zoologie. LXIv (1898), 648-696.

Castle, W. E., 1900. The metarnerism of the Hirudinea. Proceedings American Academy of Arts and Sciences. Xxxv (1900), 285-303.

Leuckart, R., 1894. Die Parasiten des Menschen. 2d ed. Leipzig, 1894. Bd. v. Leif., 5.

Moore, J. Percy, 1898. The leeches of the U. S. National Museum. Proceedings United States National Museum. xxI (1898), 543-563.

Moone, J. Percy, 1900. A description of Microbdella biannulata, with especial regard to the constitution of the leech somite. Proceedings Academy Natural Sciences Phila., 1900, 50-73.

Mogun-Thndon, 1846. Monographie de la famille de Hirudinées. 2d ed. Paris, 1846.

Whitman, C. O., 1886. The leeches of Japan. Quarterly Jour. Micro. Science. Xxvi (1886), 317-416.

Whitman, C. O., 1892. The metamerism of Clepsine. Festschrift zum 70 ten Geburtstage R. Leuckart: (1892), 385-395. 


\section{DESCRIPTION OF FIGURES.}

\section{Plate 12.}

Figs. 1 to 9 represent Hirudinaria blanchardi.

Figs. 1,2. Ventral and dorsal views, respectively, of a typical large specimen, $\times 5$. The somites are indicated by Roman numerals on the left; the numbers on the right are of the annuli, counted from the prostomium, while the symbols included within parentheses show their theoretical value. The eyes and metameric sensillæ are shown in heavy black, the "gobletshaped sense organs" and the "conical sense organs" as small dots. Except that all of the goblet-shaped organs are not represented, the position and number of the sense organs is indicated as accurately as possible. An attempt has also been made to have the boldness of the lines correspond with the depth of the interannular furrows.

Fig. 3. A semidiagrammatic view of the dorsum of the posterior end of the same specimen, $\times 5$. The metameric sense organs only are represented. The dotted line across annulus Xxiv $a 3$, indicates its partial subdivision into two. The somites and annuli are indicated as in fig. 2 .

FrG. 4. Slightly more than the right half of somites XV and XvI of the largest specimen, $X 3$. The whole surface, dorsal and ventral, is shown as though flattened out, and every topographical feature of XV has been drawn with the greatest care. On XvI and on the middle portion of $\mathrm{XV}$ the color pattern of a small specimen has been plotted to show its relation to the sensillæ, etc. The intensity of the black pigment is indicated by the closeness of the stippling. $d m$, dorsi-meson; $m$, extreme lateral margin; $v m$ (the exact margin of the figure), the ventrimeson; $n p$, nephridiopore; $m d$, median-dorsal; dl; dorso-lateral; dma, dorso-marginal; $s m$, supra-marginal; sbm, submarginal; $v m \alpha$, ventro-marginal; and $v l$, ventro-lateral sensillæ.

FiG. 5. A median dorsal jaw, $\times 33$. Outline as seen from the right side. The teeth and papillæ are shown.

Fig. 6. Transverse section of a jaw shown in outline, $\times 33$. The cut is near the anterior end, and shows one of the larger denticles and the central mass of gland ducts which open partly on the dentigerous margin, partly on the lateral faces of the jaw. $d$, denticle; $p$, papillæ; $g d$, axial mass of ducts.

Fig. 7. Partial representation of the reproductive organs from the dorsal aspect, $\times 6.5$. On the left side the first testis only is shown, and the ductus ejaculatorius is drawn forward to show the epididymis. $t 1-t 11$, the eleven testes; $v d$, the vas deferens; de, ductus ejaculatorius (sperm sac); $e p$, epididymis; $p s$, penis sheath (atrium); ov, ovary; odc, common oviduct;
$v g$, vagina.

Fig. 8. Outline of terminal portion of male duct, seen from the left side, $\times 6.5$. $\delta$, male pore; other letters as in fig. 7 .

FIG. 9. Outline of the female organs of the largest specimen, somewhat dissected, $\times 6.5$. lov and rov, left and right ovaries; gla, albumen gland; odc, common oviduct; $v g$, vagina; $b$, female bursa; + , female pore.

\section{Plate 13.}

Figs. 10 to 17 represent Diplobdella antillarum.

Figs. 10, 11. Semidiagrammatic figures of the anterior and posterior ends of the body viewed from the dorsum. $\times$ (about) 5 . The somites and annuli with their values are indicated as in figs. 1,2 , and 3 , but the metameric sensillæ are indicated by circles. On somite xIv the ventral sensillæ are shown. Sensillæ lettered as in fig. 4.

Fig. 12. The sex pores and neighboring structures. $\times$ (about) 5 .

Fig. 13. A left lower jaw shown in outline and as a transparent object. $\times 56$. The denticles, the course of the gland ducts from the central mass, and the arrangement of some of the muscles are shown.

Fig. 14. Reproductive organs from above. $\times 6.5$. The left testes are omitted, and the lettering is as in fig. 7 , except $p g l$, prostate glands.

Figs. 15, 16. Two transverse sections through the atrium. $\times 26$. The section shown in fig. 15 is five sections anterior of 16 . $\widehat{\jmath}$, male pore opening from bursa; $m$, median common part of duct opening into male bursa; $m b$, muscular wall of atrium; de, ductus ejaculatorius; ep, epididymis; $p g l$, prostate glands; $l m$, longitudinal muscle layer; $\mathrm{cm}$, circular muscle layer; $n$, nerve cord.

Fig. 17. Outline of alimentary canal. $\times$ (about) 5 . The Roman numerals indicate somites, and show the extent of the several regions.

Figs. 18, 19, and 20 are, respectively, nearly anterior, ventral, and right lateral views of the female reproductive organs of Hirudinaria javanica. $\times 10$. Lettering as in fig. 9 . 


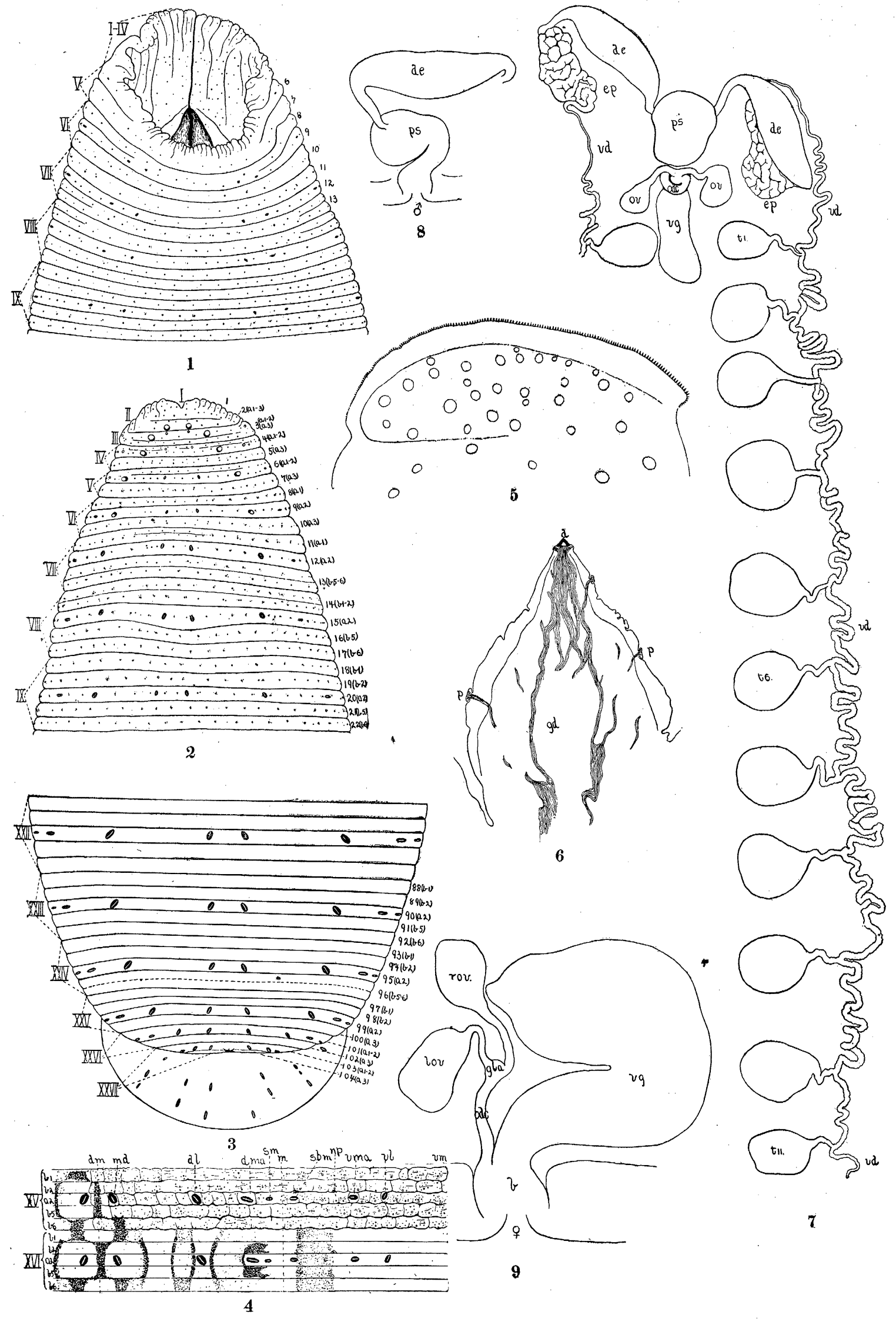




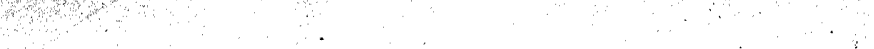



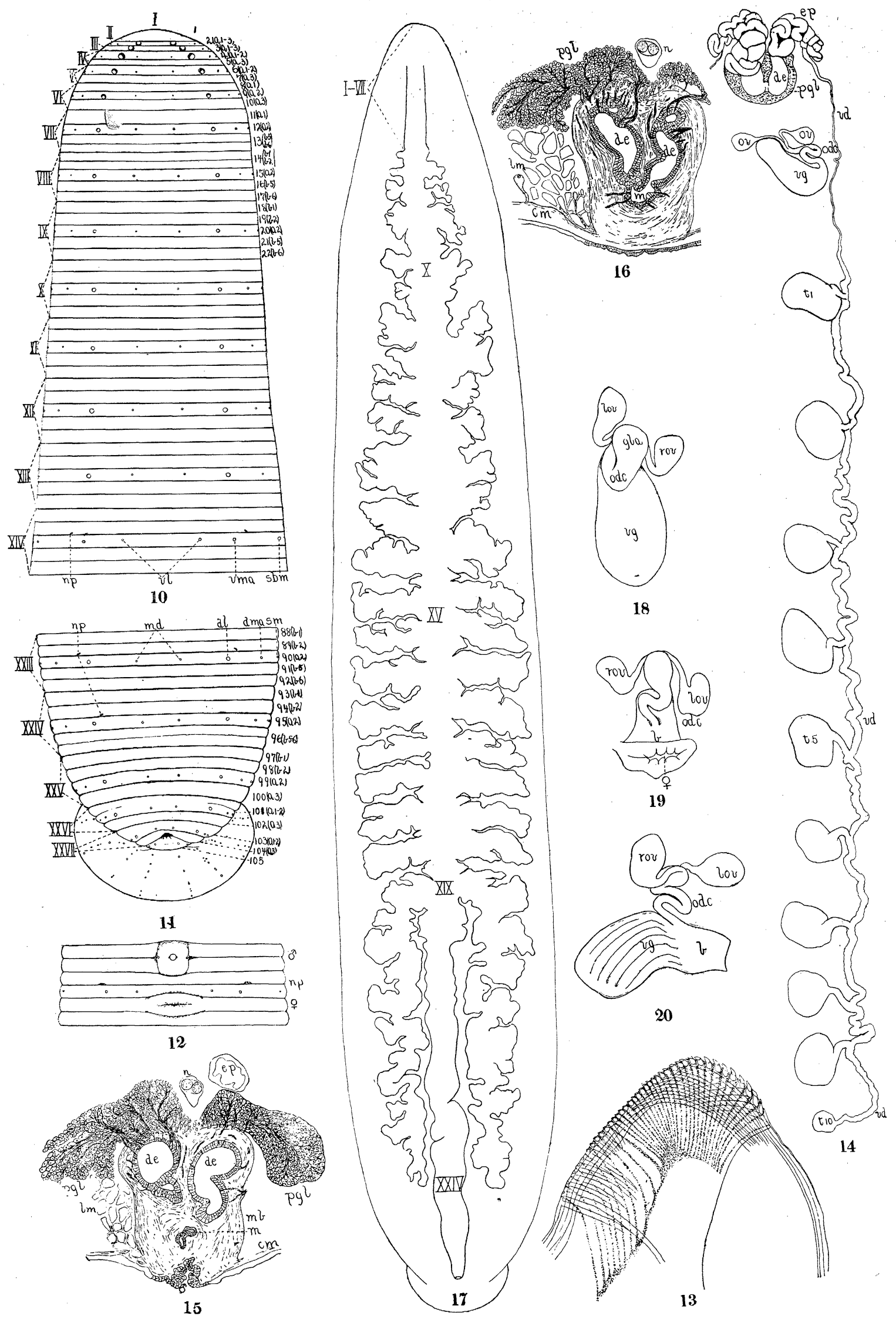

